DOSSIÊ TEMÁTICO: Saberes docentes de intelectuais negras: mediações outras frente ao ethos acadêmico

dOI https://doi.org/10.22481/praxis.v15i32.5043

\title{
EMANCIPACIÓN Y DESCOLONIZACIÓN: TENSIONES, LUCHAS Y APRENDIZAJES DE LOS INVESTIGADORES/AS NEGROS/AS EN LA EDUCACIÓN SUPERIOR
}

\author{
EMANCIPATION AND DECOLONIZATION: TENSIONS, STRUGGLES AND \\ LEARNING OF BLACK RESEARCHERS IN COLLEGE EDUCATION
}

\section{EMANCIPAÇÃO E DESCOLONIZAÇÃO: TENSÕES, LUTAS E APRENDIZAGENS DE INVESTIGADORES/AS NEGROS/ASNA EDUCAÇÃO SUPERIOR}

\author{
Anny Ocoró Loango \\ Universidad Nacional de Tres de Febrero - Argentina
}

\begin{abstract}
Resumen: Este artículo busca contribuir al debate sobre los/as investigagores negros/as en la educación superior, poniendo de manifiesto como su ingreso y su presencia interpelan la desigualdad de oportunidades y las fuertes barreras raciales que existen en estos espacios académicos. Así mismo, analiza cómo en estos espacios se sostiene el racismo institucional y epistémico.

Partiendo de una mirada a experiencias personales, intenta dar cuenta de las luchas de los/as investigadores/as negros/as en la educación superior, así como las transformacioes que su inserción en la vida universitaria genera. Finalmente, hace visible los aportes que realizan los/as investigadores/as negros/as en la configuración un proyecto político, epistémico y contrahegemónico a favor de la transformación de las estructuras de opresión racial y cultural en América Latina.
\end{abstract}

Palabras clave: Racismo epistémico; linvestigadores/as negros/as; Descolonización; Interculturalidad; Educación superior

\begin{abstract}
This article seeks to contribute to the debate on the black researchers, in the higher education, showing how their income and their presence interpellate the inequality of opportunities and the strong racial barriers that exist in these academic spaces. He also analyzes how hegemonic epistemologies support institutional and epistemic racism. Starting from a look at personal experiences, she tries to account for the struggles of black researchers in higher education, as well as the transformations that their insertion in university life causes. Finally, it seeks to make visible the contributions made by black researchers in the configuration of a political, epistemic and counterhegemonic project in favor of the transformation of racial and cultural oppression structures in Latin America.
\end{abstract}

Keywords: Epistemic racism; Black researchers; Decolonization; Interculturality; Higher education 
Resumo: Este artigo busca contribuir para o debate sobre a pesquisadores negros/as, no ensino superior, mostrando como sua renda e sua presença interpelam a desigualdade de oportunidades e as fortes barreiras raciais existentes nesses espaços acadêmicos. Ele também analisa como as epistemologias hegemônicas apóiam o racismo institucional e epistêmico. A partir de um olhar sobre as experiências pessoais, ela tenta explicar as lutas dos pesquisadores negros no ensino superior, bem como as transformações que a sua inserção na vida universitária gera. Por fim, procura-se tornar visíveis as contribuições dos pesquisadores negros na configuração de um projeto político, epistêmico e contra-hegemônico em favor da transformação das estruturas de opressão racial e cultural na América Latina.

Palavras-chave: Racismo epistêmico; Pesquisadores negros; Descolonização; Interculturalidade; Ensino superior

Si no se ha logrado la igualdad de oportunidades, no es sólo porque la sociedad es desigual, sino también porque el juego escolar es más favorable para los más favorecidos. (DUBET, 2006, p. 15).

Este artículo busca contribuir al debate sobre los/as investigadores/as negros/as en la educación superior, poniendo de manifiesto como su ingreso y su presencia interpelan la desigualdad de oportunidades y las fuertes barreras raciales que existen en estos espacios académicos. Así mismo, analiza cómo en estos espacios se sostiene el racismo institucional y epistémico.

Partiendo de una mirada a experiencias personales, intenta dar cuenta de las luchas de los/as investigadores/as negros/as en la educación superior, así como las transformaciones que su inserción en la vida universitaria genera. Finalmente, hace visible los aportes que realizan los/as investigadores/as negros/as en la configuración un proyecto político, epistémico y contra-hegemónico a favor de la transformación de las estructuras de opresión racial y cultural en América Latina.

\section{Consideraciones generales sobre la raza y el racismo}

El dominio colonial de Europa sobre América que significó el despojo de sus riquezas, el saqueo de sus recursos naturales y el genocidio de sus pueblos, también supuso la instauración de un sistema de ideas que, al tiempo que postulaba la existencia de razas, afirmaba la superioridad "natural" de los europeos. Ese discurso construyó una imagen en la que el europeo era "el civilizador", sinónimo de progreso y los otros pueblos, eran “inferiores" y debían ser dominados. Esta ideología racista, impuesta para justificar la explotación y legitimar las desigualdades sociales “(...) tiene una base más bien política, 
ideológica y cultural y no biológica, aunque su soporte principal siempre ha sido el cuerpo humano, el color de la piel, los rasgos y evidencias fisicas” (BELLO; PAIXÃO, 2009: 42).

La Raza es un concepto moderno que comenzó a tomar forma con el surgimiento de la economía mundial, en la cual la conquista de América, la creación de los imperios marítimos, la esclavización de africanos, constituyen pilares en su genealogía (Winant, 2000). Aun cuando es un lugar común asociar la raza al color de la piel, esta es una invención social, producto de la modernidad, que excede las elaboraciones teóricas planteadas y avaladas por el racismo científico del siglo XIX y comienzos del XX.

Pese a que desde el punto de vista científico las razas no existen, y que la ciencia proclamó la inutilidad de la asociación de raza y biología, la idea de raza y su legado histórico se mantuvieron. No se puede negar que la "raza" constituye una categoría social poderosa que domina el imaginario de identidad, y tiene efectos concretos en las estructuras sociales y en la vida cotidiana de las personas. La existencia de razas se ha naturalizado, al punto de que múltiples prácticas cotidianas, relaciones entre las personas y oportunidades sociales, se organizan en función de las apariencias fenotípicas.

El racismo no es un fenómeno estático y el hecho de que no se manifieste de forma extrema y visible, no significa que no exista. Vivimos en sociedades racializadas en las que "el racismo se convierte en un principio organizativo de las relaciones sociales" (BONILLA-SILVA, 2011, p. 687). Como bien afirman Euclides y da Silva

[...] o racismo impera em diversas instâncias da sociedade, impedindo que negros e brancos tenham o mesmo acesso às possibilidades circunscritas no mundo moderno. Um exemplo disso é o racismo institucional, que, assim como os demais tipos de racismo, é camuflado, velado, mas nem por isso deixa de ser presente, fazendo vítimas negras e negras e impedindo seu acesso a determinados espaços sociais. Trata-se de impedir institucionalmente o acesso de quem está na categoria racial negra a bens e serviços públicos, tais como assistência educacional, saúde dentre outros. (2016, p. 105).

En los nacientes estados nacionales de América Latina, el mito de la identidad nacional blanco-mestiza y de la democracia racial, contribuyeron a negar la historia negra, al tiempo que construían una imagen del negro como ajeno al progreso y a los valores de la ciudadanía moderna. Así garantizaron que el orden racial, que imponía la discriminación y el racismo como formas de disciplinamiento social, dejara fuera del campo de visibilidad la opresión hacia el negro y lo responsabilizara a este de su propia condición. De esta manera, la ideología del mestizaje no sólo encubre y niega la existencia del racismo (Curiel, 2007), sino 
que "reafirma la supremacía cultural, y a veces biológica, de herencias blancas hispánicas" (REYES-SANTOS, 2008, p. 7).

\section{Racismo epistémico en las prácticas académicas}

Salvo excepciones recientes, como el caso brasileño, las investigaciones y estudios sobre la diáspora africana en América Latina, en general, han estado conducidas por investigadores blancos. Esta academia blanca y mayoritariamente masculina ha monopolizado el campo de los estudios sobre las poblaciones negras en América Latina desde su surgimiento. Brasil, Cuba y más tardíamente Colombia, lideraron "el nacimiento de los estudios afro en América Latina" (HURTADO, 2010, p. 80). Cuba y Brasil tienen una larga tradición en los estudios sobre la población negra. En Cuba, Fernando Ortiz, a principios del siglo $\mathrm{XX}$, inauguró el campo de los estudios afrocubanos y el estudio científico del negro en Cuba (GODOY, 1966). En Brasil, Perdigão Malheiros y Nina Rodriguesson son precursores de los estudios afro en ese país (Moura, 1988). En Colombia estos estudios surgieron más tardíamente. La población negra emergió como "objeto" de investigación antropológica en la década del 50, con los trabajos de Aquiles Escalante. Dos décadas más tarde se destacaron los trabajos de Nina S. de Friedemann, una de las pioneras en los estudios de poblaciones negras en Colombia (CUNIN, 2003; RESTREPO, 1998).

En América Latina, la presencia de investigadores/as negros/as en las Instituciones de Educación Superior (IES) es aún minoritaria. Dentro de los docentes universitarios y los equipos de investigación están sub-representados y en muchos casos, su presencia está invisibilizada. Hay además una ausencia de la historia y las epistemologías negras en los programas académicos de las IES. La producción intelectual negra es poco tenida en cuenta o desconocida en las bibliografías de los programas académicos. Tanto es así que, ya sea "de forma consciente o inconscientemente, raramente los autores negros están en las bibliografias de los cursos ofrecidos en las universidades" (FIGUEIREDO; GROSFOGUEL, 2007, p. 36).

La reducida presencia negra en las IES, sin duda tiene relación con las grandes dificultades que, enfrentan los afrodescendientes a lo largo de sus trayectorias educativas, tanto en el nivel medio, como en el acceso a la educación superior, pero de ninguna manera, es esta la única, ni la principal de sus causas. En efecto, esa evidente y desproporcionada ausencia no puede explicarse sin aludir al fuerte racismo institucional que aún pervive en los 
sistemas educativos y en las IES. Una compleja trama de privilegios, le otorga al blanco ventajas que no son expresas, sino que están entretejidas con hilos invisibles y no pueden entenderse sin hacer una lectura que tenga en cuenta la clase, la raza y el género.

Los espacios académicos no son ajenos al racismo que impera en la sociedad. La negación de los negros/as como sujetos productores de conocimiento, así como el hecho de reducirlos a una especie de minoría de edad, es una forma común de racismo epistémico que a veces pasa inadvertida. El racismo, enquistado en los espacios académicos, justamente no reconoce el estatus de igualdad cognitiva del otro/a, subalterniza sus conocimientos y su cultura, contribuyendo a acrecentar y reproducir su desigual vinculación en los campos de producción de conocimiento y en las estructuras de lasociedad.

La ideología racista que ha construido a la población negra como desprovista de capital social y cultural, instaurada por el colonialismo, aún continúa vigente asignando jerarquías, estatus y el acceso a oportunidades, según el color de la piel. Se puede entonces argumentar que, si bien el racismo tiene anclaje en las prácticas individuales, es decir es ejercido por individuos, tiene también un fuerte componente estructural. Entonces esta racialización de los conocimientos debe ser leída en términos estructurales, ya que no sólo es producida por individuos o grupos que asumen como inferiores las formas de conocimiento de otros, sino que es constitutiva de la tradición de pensamiento occidental. Precisamente "Occidente es considerado como la única tradición legítima de pensamiento para producir conocimiento, y la única con acceso a la "universalidad", "racionalidad” y "verdad". El racismo epistémico considera que el conocimiento "no occidental" es inferior al conocimiento "occidental” (GROSFOGUEL, 2012, p. 54).

\section{Extractivismo académico y cultural}

Los activistas del movimiento afro han puesto de manifiesto la existencia de tensiones con el campo académico, señalando que gran parte de lo que se investiga tiene muy poco impacto sobre sus comunidades y los efectos prácticos de dichas investigaciones resultan muy reducidos. En la interpretación de estos activistas, la investigación académica resulta asociada a una forma de saqueo, una suerte de "extractivismo" cultural y académico que se acerca a las comunidades y se nutre de ellas sin dejar ningún beneficio para estas. Denuncian una suerte de mercado académico en el cual algunos académicos establecen relaciones con organizaciones afro que les son funcionales para desarrollarse dentro del 
campo académico y en definitiva se olvidan de estas comunidades, una vez conseguidos sus objetivos.

En algunos espacios académicos coexisten el apoyo y la contradicción ya que se puede observar cómo al mismo tiempo que se habla sobre la negritud, invocando sus derechos, no se la toma en cuenta como interlocutor en esa discusión. Para estos grupos académicos, la población negra es un objeto de estudio o en muchos casos una mera fuente de información que no tiene participación en el desarrollo científico y en la transmisión de ese saber.

En una entrevista, Walter Mignolo, afirma que, en cierto modo, el conocimiento funciona en forma análoga a la economía: se basa en la existencia de "centros de poder" que son la referencia en el campo, y "regiones subalternas" que dependen de los primeros (MIGNOLO, 2003). Se podría agregar que esta relación de superioridad también está atravesada por una cuestión racial: el conocimiento está racializado. Fanón señala que, antes de atribuir validez a un conocimiento, se mira primero el color de la piel. Cuando es negro el cuerpo de quien lo enuncia, el conocimiento es considerado seudo científico, cosa que no ocurre cuando se trata de blancos que estudian a los negros. Se racializan como inferiores los conocimiento de cuyos cuerpos, culturas e historias no son "representativos" de la cultura occidental (FANÓN, 1973). Estas situaciones no son sino una muestra más del racismo epistémico presente en nuestras sociedades latinoamericanas.

A pesar de las prácticas desconocedoras de los saberes de los sujetos de quienes habla y del lugar de los/as académicos/as negros/as, con las que necesariamente debemos ser críticos y luchar para que desaparezcan, debemos decir también que son muchos los/as intelectuales o académicos no negros que, de distintas maneras, acompañan al movimiento negro, Sus aportes han contribuido a la generación de pensamiento crítico para repensar las prácticas políticas y organizativas del movimiento negro. Las injusticias, asimetrías y los profundos conflictos que enfrentan nuestras sociedades nos exigen tender puentes con otros y construir con todos/as los que tengamos la esperanza de otros mundos posibles. Nuestras miradas, posiciones de sujeto y prácticas políticas también tienen que ser repensadas, deconstruidas y esto sólo es posible si debatimos, nos encontramos y construimos con otros. Esto no invalida que se creen espacios de representación y discusión desde los grupos indígenas o negros. Cabe destacar también los aportes de muchas/os intelectuales africanos/as y de la diáspora, surgidos del movimiento negro que, desde distintas perspectivas, han aportado en el proceso de emancipación y politización del mismo. Por 
supuesto, también, cabe mencionar, el aporte del feminismo negro, cuya riqueza teórica ha posicionado miradas interseccionales para analizar la realidad de las mujeres negras.

Debemos seguir ganando espacios de representación para la negritud y en especial para las mujeres negras, así como también seguir cuestionando las lógicas y prácticas racistas y monopólicas que existen en el campo académico. Este es un debate que viene creciendo,está tomando fuerza en varios espacios y no va detenerse. Es una discusión en la que debemos participar. Es necesario un debate político y ético sobre las prácticas académicas y más aún en aquellos espacios o enfoques que se definen decoloniales, poscoloniales y subalternos. Las mujeres negras no podemos seguir aceptando que las académicas "blancas" hablen de feminismo negro sin las mujeres negras. Estas herencias coloniales y eurocéntricas en el campo del saber, deben ser superadas. Como bien han manifestado muchos/as investigadores/as brasileños/as: no podemos seguir aceptando que hablan de nosotros/as sin nosotros/as.

\section{La presencia negra en las universidades}

En América Latina, las políticas orientadas desde criterios étnicos raciales son un fenómeno más bien reciente. No fueron parte de la agenda de los Estados sino hasta bien entrada la última década del siglo XX. En los últimos años, aun cuando no son suficientes y cuentan con limitados recursos, se han venido desarrollando diversas experiencias y modalidades de inclusión de los pueblos afrodescendientes e indígenas en la educación superior en varios países de América Latina (MATO, 2009).

Las acciones afirmativas han favorecido e incrementado la presencia negra en las universidades. En la región, Brasil es el principal referente en torno a la aplicación de políticas de acción afirmativa para la población negra ${ }^{1}$. Es además pionero en estas luchas, al ser el primer país de la región en proponer cuotas para negros e indígenas. Las acciones afirmativas también fueron acogidas por la ONU. La Conferencia Mundial contra el Racismo, la Discriminación Racial, la Xenofobia y las Formas Conexas de Intolerancia, Durban (2001) instó a los Estados a desarrollar políticas de acción afirmativa para los afrodescendientes y reconoció que el racismo somete a la población afrodescendiente a una situación de mayor marginación y perjuicio. Tanto las declaraciones finales como los

\footnotetext{
${ }^{1}$ Brasil es indiscutidamente el país que mayores desarrollos presenta en la implementación de acciones afirmativas. En la actualidad un gran número de universidades estaduales y federales cuentan con acciones afirmativas. Otros países de la región también han venido implementando políticas en esa dirección (Colombia, Ecuador, Bolivia entre otros).
} 
programas de acción de la Conferencia Preparatoria de Santiago y de la Conferencia Mundial de Durban, se manifestaron acerca de la urgencia de que los Estados diseñen estrategias de lucha y establezcan acciones afirmativas contra el racismo, la discriminación racial, la xenofobia y todas las formas conexas de intolerancia ${ }^{2}$. Las acciones afirmativas son medidas encaminadas a proteger los derechos fundamentales de los grupos marginados: los afrodescendientes y los pueblos indígenas, así como de otras víctimas de racismo como los migrantes. La comunidad LGBT, las mujeres la población discapacitada, la población reinsertada entre otros, también pueden ser objetivo de aplicación de estas medidas y estas políticas no se limitan a los cupos o cuotas de acceso a la educación superior ni a los grupos étnicos. Esta es sólo una de las formas posibles de llevarlas a cabo.

La presencia negra en las universidades, y en especial la inserción de las mujeres, está produciendo cambios, no solo en la vida de las mujeres negras sino también en la universidad. Esta es una importante conquista ya que históricamente estos espacios estuvieron vedados para la población negra. En efecto, "a ausência de negros em espaços privilegiados como o Ensino Superior ou cargos que culturalmente têm a presença majoritária de brancos é sinal de que há, embutido na lógica social, um recorte hierárquico de raça no qual se têm claramente definidos lugares e papéis sociais (EUCLIDES; DA SILVA, 2016, p. 106).

El ingreso permanente y sostenido de la población negra en la universidad, interpela la amplia desigualdad de oportunidades, las fuertes barreras raciales que existen en la educación superior y el racismo institucional y epistémico. Lograr acceder a la educación superior es el resultado de esfuerzos personales y familiares. Es frecuente que los negros/as que acceden a la educación superior sean la primera generación en la familia que lo hace. Los estudiantes negros provienen en su mayoría de sectores sociales que no han tenido la oportunidad de acceder a un nivel de educación superior, incluso sus padres escasamente alcanzan el nivel de educación primaria o secundaria incompleta. Estamos ante el caso de grupos marcados por las fuertes desigualdades raciales que, muchas veces, gracias al apoyo de las políticas de acción afirmativa, han logrado acceder a la educación superior. Especialmente las mujeres negras han venido ganando espacios en la educación superior,

\footnotetext{
${ }^{2}$ Particularmente para América Latina la agenda de Durban fue muy significativa y representó un salto importante en la política para los afrodescendientes. Si bien el movimiento negro había logrado algunas conquistas en la región, previas a Durban, como las reparaciones territoriales en el caso de la ley 70 en Colombia y los quilombos en Brasil, la Conferencia legitimó los reclamos y representó un salto cualitativo en las políticas raciales, ya que la mayoría de los Estados se comprometió a desarrollar políticas a favor de los afrodescendientes. En efecto, Latinoamérica fue la región del mundo en la que mayor relevancia cobró las disposiciones de lucha contra el racismo acordada en Durban (LAO-MONTES, 2009).
} 
participando en este juego de relaciones de poder/saber, que históricamente les estaba vedado.

Es interesante notar cómo para quienes tienen generaciones de exclusión sobre sus espaldas, la decisión de ingresar a la universidad adquiere una intensa fuerza simbólica. En efecto, el desafío de romper el límite que el contexto histórico-social inexorablemente le asigna a él y su grupo poblacional, adquiere una trascendencia que va más allá de lo personal.

Sin duda, la presencia de las poblaciones negras en la universidad desafía los roles y los lugares socialmente asignados por el racismo. El racismo es un mecanismo de control social que busca garantizar la sobrevivencia de las jerarquías raciales y de los privilegios que atesoran algunos sectores. El racismo está ahí vigilante para evitar que cruces la línea permitida por el orden racial imperante. De modo que un cuerpo que expone su negrura en "un espacio en el que no deberìa estar", es disruptivo porque ayuda a desnaturalizar la mirada que inferioriza a estas poblaciones y que les asigna roles ajenos al trabajo intelectual. También contribuye a visibilizar las resistencias del pueblo negro a ser reducidos y despojados de sus capacidades y fundamentalmente, ese cuerpo negro que empieza a ennegrecer la universidad, representa un aporte a favor de la transformación de las estructuras de opresión racial y cultural en América Latina. Es imprescindible superar la impronta excluyente que la educación superior latinoamericana arrastra desde sus orígenes, para vencer las grandes ausencias indígenas y afrodescendientes.

\section{Los dilemas de la observación participante y el efecto liberador de la investigación}

Mis experiencias como profesora e investigadora negra en la educación superior, no pueden entenderse sin tener en cuenta los procesos históricos de negación e invisibilización que la población negra sufrió en la Argentina ${ }^{3}$. En mi trabajo, la observación participante es una herramienta central y me ha abierto la puerta un mundo de representaciones y percepciones que de algún modo explican el lugar del negro en la cultura y la sociedad argentina.

Vale la pena comentar aquí la dinámica que me tocó vivir cuando en realicé el trabajo de campo para mi tesis de maestría entre 2009 y 2010 en las escuelas de la Provincia

\footnotetext{
${ }^{3}$ En Argentina, las élites imaginaron un modelo de nación en el cual la identidad del indio y del negro tenía que disolverse, en pos de un modelo de construcción de nación basado en los patrones de la ciudadanía europea. La preocupación por "mejorar la raza" agenciada desde las élites, tuvo a Europa como el horizonte y el estandarte de la civilización y el progreso, dejando en el olvido a las poblaciones negras e indígenas.
} 
de Buenos Aires ${ }^{4}$. Como investigadora negra, mi sola presencia en las escuelas desencadenó reacciones diversas, caracterizadas por el extrañamiento, la curiosidad ${ }^{5}$. Mi llegada a las instituciones educativas estuvo signada por continuas miradas de sorpresa, expresadas de manera más directa en los alumnos pero también en los docentes. De manera semejante, al hablar con los docentes resultaba notorio que intentaban omitir la palabra negra o negro en un afán por mostrar neutralidad en su descripción (TRAVERSO, 2005). Algunos sustituían la palabra "negro" por mulato, moreno o negrito, en un intento por entrar en un clima de familiaridad con la investigadora, aludiendo quizá a la connotación negativa que reviste el término "negro".

La mirada se convierte entonces en un dato importante de la investigación porque hace visibles las representaciones que se construyen sobre los otros a quienes se les presume ajenos. Una de las maestras al ver la mirada de extrañamiento y de curiosidad, expresada por los niños ante mi presencia, manifestó: "los niños se quedan impactados porque no lo ven, ellos lo tienen como un cuento, que los negros estaban ahí, pero nada más, por ahí lo tienen como que es algo que está pero no tan cerca". Otra de ellas manifestó: "hay chicos que se quedan mirándote, llama la atención, no es habitual, en capital quizá si por el turismo pero no es habitual".

Las palabras de las maestras, suscitadas a partir de la reacción que generó la presencia de una investigadora negra en la institución escolar, me ofrecieron una primera información del tema en cuestión: los negros son algo que no se ve, que no está en la Argentina, son parte de un relato, de un cuento, para usar las palabras de una de las maestras, el negro como un tipo de memoria ficcional que sólo existe ahí, cada 25 de mayo. Era el primer encuentro con un campo de trabajo en el que emociones, gestos, miradas hablaban “del objeto", pero también de la cultura escolar, el lugar del otro, el lugar de los negros en la Argentina. Investigar las representaciones de los negros en los actos escolares del 25 de mayo revelaba la naturalización de concepciones de docentes, de la sociedad Argentina sobre la negritud, pero a su vez nos invitaba a efectuar una ruptura con la tendencia a naturalizar aquello que a veces tomamos como dado y problematizarlo, desnaturalizarlo, para asumir lo social como parte de una construcción histórica de la que participan los sujetos.

\footnotetext{
${ }^{4}$ En esta investigación analizaba las presentaciones que existen en los actos escolare del 25 de mayo en Argentina. Esta efeméride nacional se festeja todos los 25 de mayo y en la escuela se realizan actos conmemorativos, en los que, comunmente, aparece niños disfrazados de negros que vivían en laépoca colonial. ${ }^{5}$ En este periodo la migración negra no era tan numerosa y visible como lo es en la actualidad.
} 
¿Cómo llegó la Argentina a construir una visión de extrañamiento frente a los negros?, ¿esas miradas continuas en ocasiones invasivas, puestas sobre los cuerpos negros, cómo llegaron a estructurarse, cómo y en qué momento emergieron?, ¿qué procesos, imaginarios y discursos las estructuraron?, ¿no llegaron los negros acaso a constituir porcentajes poblacionales muy significativos en la Argentina?, ¿no contribuyeron acaso a gestar la nación?. Todas estas situaciones desencadenadas desde un primer contacto con el campo de trabajo nos ponían frente a la necesidad de historizar lo que sucedía, poniendo en evidencia las arbitrariedades históricas de las creaciones de la humanidad en contextos de lucha simbólica y de relaciones de poder (Bourdieu, 1970). Esto necesariamente nos conducía a relativizar y comprender que las clasificaciones, categorías, las formas de nombrar el mundo están inmersas o son producto de relaciones de poder, nos exigía situar los fenómenos y los procesos en relación con las estructuras a las que pertenecen y comprender de qué manera se involucra la educación es estos procesos.

Muchas de las concepciones encontradas en la escuela no son exclusivas de ésta sino que existen en la cultura y se han configurado históricamente. Además están caracterizadas por dar al negro un lugar subalterno; una historia que ha cristalizado en representaciones estereotipadas y racializadas del negro. En cierto modo, el investigar sobre la negritud en la Argentina me dio seguridad y confianza para estar en un país que enciende reflectores sobre aquellos que consideran diferentes. La investigación ha sido para mí un proceso de liberación de los preconceptos, de desnaturalización y de autoafirmación de mi negritud. Me he vuelto más negra en el país que se presume más "blanco" de América Latina.

\section{De la universidad monocultural a la apertura intercultural}

El carácter monocultural de las universidades y sus modos de relacionarse con las poblaciones indígenas y afrodescendientes y sus saberes, constituye uno de los mayores obstáculos para construir sistemas educativos interculturales. A lo largo de su historia las universidades han favorecido el eurocentrismo como paradigma de formación e investigación, privilegiando el conocimiento producido dentro del marco científico/académico y han contribuido a calificar los conocimientos y saberes ancestrales o tradicionales como folclóricos, exóticos, pre-científicos o como obstáculos para el conocimiento. Particularmente, las ciencias sociales han asumido, por mucho tiempo, que el 
conocimiento académico/científico es "universal", descalificando y tildando de "locales" a los modos de producción de conocimiento de los pueblos indígenas y afrodescendientes.

Existen fuertes resistencias para lograr la apertura y la democratización del acceso a la educación superior, al tiempo que prevalece la discriminación racial y el racismo. Aunque hay iniciativas de inserción de contenidos referentes a la historia y cultura africana y de la diáspora africana, encontramos muchos obstáculos por causa del poder hegemónico de base eurocéntrica presente en nuestros claustros universitarios. La práctica de los/as investigadores/as negros/as se ve afectada por múltiples dificultades y problemas ante la falta de democratización del acceso a la educación superior y la falta de garantías de

inclusión de los problemas raciales en ese espacio. En Brasil, el país que más alcances presenta a favor de la población negra, las instituciones de Enseñanza Superior resisten fuertemente los cambios epistemológicos, en sintonía con la diversidad étnico-racial, provocados por la presencia de negros e indígenas en las universidades públicas y privadas del país (OCORÓ; DA SILVA, 2017).

En definitiva, para avanzar en el desarrollo de políticas interculturales o en la interculturalización de la educación superior, es necesario someter a debate no sólo la participación reducida de las poblaciones negras e indígenas en la educación superior, sino también el discurso hegemónico eurocéntrico y las relaciones de poder mediante las cuales se han jerarquizado los saberes y los conocimientos de las comunidades indígenas y de los pueblos negros. En la actualidad "la educación superior se ve (...) desafiada en su esencia universalista cuando se demanda el reconocimiento de otras epistemologías igualmente valederas y pertinentes como esencia del ideal de respeto de la diversidad, más allá de simples medidas de ingreso a la universidad con programas de atención diferenciada o de adecuaciones curriculares" (SICHRA, 2010, p. V).

Avanzar hacia la descolonización y el pluralismo epistémico es fundamental para poder construir relaciones que recuperen y valoricen los conocimientos y saberes epistémicos de los pueblos negros e indígenas en América Latina. No hay interculturalidad posible sin si no se confrontan las epistemologías hegemónicas y incorporando el conocimiento de los grupos subalternos. Como bien señala Lander (2000)

Las actuales estructuras disciplinarias de las universidades latinoamericanas con su parcelamiento burocrático de los saberes, (...) tienden a acentuar la naturalización y cientifización de la cosmovisión y la organización liberal/occidental del mundo, operando así como eficaces instrumentos de colonialismo intelectual. (LANDER, 2000, p.43). 
Esto pone en evidencia la severa limitación de estos espacios para dar cabida a perspectivas y prácticas no eurocéntricas y pluralistas desde el conocimiento. Como bien afirma Bourdieu

[...] el campo intelectual, a la manera de un campo magnético, constituye un sistema de líneas de fuerza: esto es, los agentes o sistemas de agentes que forman parte de él pueden describirse como fuerzas que, al surgir, se oponen y se agregan, confiriéndole su estructura específica en un momento dado del tiempo. (LANDER, 2000, p.9).

\section{Construyendo espacios desde nuestra propia voz}

Participamos de un campo de luchas que no sólo responden a la necesidad de romper con la invisibilización y el relegamiento de los investigadores/as negros/as en los espacios académicos hegemónicos, sino que también apunta a intervenir en los debates y disputas por la producción de sentidos sobre la negritud, sobre las dinámicas afrodiaspóricas y sobre la intelectualidad negra, recuperando nuestra propia historia. Me permito mencionar la película cubana "La última cena" (1976), del cineasta cubano Tomás Gutiérrez Alea, basada en el libro "El ingenio", del historiador Manuel Moreno Fraginals. La película transcurre en una plantación azucarera a fines del siglo XVIII en Cuba. Brevemente mencionaré la escena que quiero traer a colación. El dueño de la hacienda, en un intento por lavar sus culpas, en el marco de la semana santa, invita a doce negros esclavizados a sentarse a la mesa y cenar con él, emulando el rito católico de Cristo y sus apóstoles. Durante la cena les promete que al día siguiente, viernes santo, no trabajaran. Posteriormente, ante la promesa incumplida, se desencadena una rebelión. En la escena el dueño de la hacienda y el sacerdote del pueblo discuten sobre la promesa incumplida y este último le dice que el orden y la calma no van a recuperarse porque los negros aprendieron que podían sentarse a la mesa del "amo".

Reflexionando sobre esa frase de esta película, que recomiendo, no sólo por su valor histórico sino por su utilidad para mirar nuestra condición diaspórica, en la relación de los/as investigadores/as negros/as con el campo académico sucede algo similar. Decidimos escribir e investigar desde nuestro propio lugar de enunciación, desde nuestra propia historicidad. No se trata de lograr "un lugar en la mesa" sino de construir nuestros propios espacios, visibilizando los aportes y tradiciones intelectuales negras, como una herramienta de lucha contra el racismo y la opresión. 
Si bien es importante que la población negra ingrese a las IES, esto no es suficiente. Tampoco basta con abrir espacios institucionales para que académicos e intelectuales negros esten representados y sean escuchados. Es necesario sacudir los cimientos racistas y eurocéntricos y patriarcales que limitan y cuestionan nuestra presencia en esos espacios. Combatirel racismo, el eurocentrismo y el colonialismo desde nuestra actividad académica es un camino ineludible para la construcción de justicia social para nuestros pueblos. En este sentido, los/as investigadores/as negros/as tenemos la responsabilidad histórica de contribuir a construir y difundir el conocimiento sobre la realidad social y cultural de las poblaciones negras o afrodescendientes de América Latina y del Caribe.

\section{REFERENCIAS}

BELLO, Á; PAIXAO, M. Una mirada a la situación de los derechos de los afrodescendientes en América Latina. En: Afrodescendientes en América Latina y el Caribe: del reconocimiento estadístico a la realización de derechos. Serie población y Desarrollo 87. Santiago de Chile: CEPAL, 2009.

BONILLA SILVA, E. “¿Qué es el racismo? Hacia una interpretación estructural”. En: debates sobre ciudadanía y políticas raciales en las Américas Negras. Universidad Nacional de Colombia y Universidad del Valle, editores. 2011.

BOURDIEU, Pierre. Campo de poder, campo intelectual. Editorial Montressor, 2002. BOURDIEU, Pierre. La reproducción. Fontamara, 1970.

CASTRO-GÓMEZ Santiago; GROSFOGUEL, Ramón. Prólogo. Giro decolonial, teoría crítica y pensamiento heterárquico. En: el giro decolonial. Reflexiones para una diversidad epistémica más allá del capitalismo global" Santiago Castro-Gómez y Ramón Grosfoguel (Eds.). Universidad Central -IESCO-, Pontificia Universidad Javeriana -Instituto Pensar- y Siglo del Hombre, 2007.

CURIEL, Ochy. Crítica poscolonial desde las prácticas políticas del feminismo antirracista". En: Nómadas (26). 2007.

EUCLIDES, Maria Simone; DA SILVA, Joselina. Professoras negras em universidades públicas do Ceará: das práticas de enfrentamento aos afrontamentos raciais. Revista de Ciências Humanas, Viçosa, v. 16, n. 1, p. 104-116, jan./jun. 2016

FIGUEIREDO Angela, GROSFOGUEL, Ramón. ¿Por qué não Guerreiro Ramos? Novos desafios a serem enfrentados pelas Universidades Públicas Brasileiras. Ciência e Cultura (SBPC), v. 59, p. 36-41, 2007.

FANON, Frantz. Piel negra, máscaras blancas. Buenos Aires: Abraxas, 1973. 
GODOY, Gustavo J. Fernando Ortiz: las Razas y los Negros. Source: Journal of InterAmerican Studies, v. 8, n. 2, Apr., p. 236-244, 1966. Published by: Center for Latin American Studies at the University of Miami Stable URL:

http://www.jstor.org/stable/165106. Accessed: 21-04-2016 16:23 UTC, 1966.

GROSFOGUEL, Ramón. Islamofobia epistémica y ciencias sociales coloniales. En: Género, raza y poder. Martínez, Alejandra y Merlino (Coord). Aldo. Colección poliedros. Editorial: EDUVIM, 2012.

HURTADO, Teodora. Los estudios contemporáneos sobre población afrocolombiana y el dilema de la producción del conocimiento "propio". Revista CS, (2), 75-99. Cali, Colombia: Universidad ICESI doi: http://dx.doi.org/10.18046/recs.i2.412, 2010.

LANDER, Edgardo. “¿Conocimiento para qué? ¿Conocimiento para quién?”, In: CASTROGÓMEZ, S. (Ed.). La reestructuración de las ciencias sociales en América Latina.

Bogotá: Instituto Pensar, 2000, p. 49-70.

MATO, Daniel. No hay saber "universal”, la colaboración intercultural es imprescindible. Alteridades, v. 18, n. 3, p. 101-116, 2008.

MOURA, Clóvis. Sociologia do negro brasileiro. São Paulo: Ática, 1988.

PONTÓN CEVALLOS, Jenny. Intersecciones de género, clase, etnia y raza. Un diálogo con Mara Viveros. Íconos. Revista de Ciencias Sociales. n. 57, Quito, enero 2017, p. 117-121. Facultad Latinoamericana de Ciencias Sociales-Sede Académica de Ecuador. 2017.

SICHRA, I. (Ed.). Perspectiva intercultural de género en la educación superior. Intercambio de experiencias y construcción de propuestas. FUNPROEIB Andes. 2019.

OCORÓ, Loango, Anny. Afroargentinidad y memoria histórica: La negritud en los actos escolares del 25 de mayo. En: Tesis de Maestría. Facultad Latinoamericana de Ciencias Sociales (FLACSO). Argentina, 2010.

OCORÓ LOANGO, Anny; DA SILVA, M. N. Educación superior y pueblos afrodescendientes en América Latina. UNESCO-IESALC, 2018.

OCORÓ LOANGO, Anny. La visibilización estadística de los afrodescendientes en la argentina en perspectiva histórica. Tramas, año 7, n. 7, p. 58-74. Montevideo, Diciembre de 2016.

REYES-SANTO, Irmary. Capital neoliberal, raza, migración: Análisis comparativo de relaciones domínico-haitianas y domínico-puertorriqueñas. En: Revue européenne des migrations internationales. En línea: http://remi.revues.org/4245. vol. 24 - n 1 | p. 13-34. Acceso, febrero 02 de 2018, 2018.

TRAVERSO Yépez, Martha. Discursos racistas: institucionalización del racismo a través de las prácticas lingüísticas. Interamerican Journal of Pshycology, anñi_v. 39 número 001. 2005. 
WALSH, Catherine. "Qué conocimiento(s)? Reflexiones sobre las políticas de conocimiento, el campo académico y el movimiento indígena ecuatoriano". Comentario Internacional, n. 2, II semestre: p. 65-77, 2001. (Quito). Disponible en http://red.pucp.edu.pe/wpcontent/uploads/biblioteca/100117.pdf, último acceso diciembre 10 de 2017.

WALSH, Catherine. ¿Son posibles unas ciencias sociales/culturales otras? Reflexiones en torno a las epistemologías decoloniales. Nomadas. n. 26, p.102-113, 2007.

WALSH, Catherine. "Las geopolíticas del conocimiento y la colonialidad del poder Entrevista a Walter Mignolo". Polis, v. 1, n. 4, Universidad Bolivariana, Santiago. 2003.

WINAN, H. "Race y race theory". In: Annual Review of Sociology. v. 26, p. 169-185, 2000.

Película "La última cena" (1976). Instituto Cubano del Arte e Industria Cinematográficos. Dirección Tomás Gutiérrez Alea.

\section{SOBRE A AUTORA}

\section{Anny Ocoró Loango}

Doctora en Ciencias Sociales de la Facultad Latinoamericana de Ciencias Sociales (FLACSO Argentina). Docente e investigadora de proyectos educativos y políticas sociales y diseño e implementación de propuestas pedagógicas. Ha trabajado en temáticas de afrodescendientes y educación, reconocimiento, diversidad cultural y políticas educativas para la igualdad racial. Es Master en Ciencias Sociales con Orientación en Educación de la misma institución y pertenece al grupo de investigación de Estudios Socioculturales de la Universidad de los Andes (Colombia) y al grupo UNIAFRO de la Universidad San Martín (Argentina). E-mail: annyocoro@hotmail.com

Recebido em: 23 de setembro de 2018 Aprovado em: 19 de novembro de 2018 Publicado em: 10 de maio de 2019 